\title{
Materials selection for eco-aware lightweight friction material
}

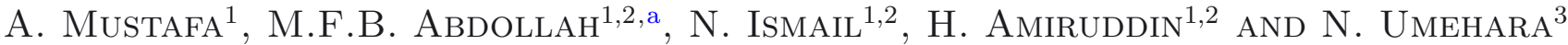 \\ ${ }^{1}$ Faculty of Mechanical Engineering, Universiti Teknikal Malaysia Melaka, Hang Tuah Jaya, 76100 Durian Tunggal, \\ Melaka, Malaysia \\ 2 Centre for Advanced Research on Energy, Universiti Teknikal Malaysia Melaka, Hang Tuah Jaya, 76100 Durian \\ Tunggal, Melaka, Malaysia \\ 3 Department of Mechanical Science and Engineering, Graduate School of Engineering, Nagoya University, Furo-cho, \\ Chikusa-ku, Nagoya 464-8603, Japan
}

Received 20 January 2014, Accepted 16 May 2014

\begin{abstract}
In the automotive industry, non-asbestos based components, such as brake pads, have been in high demand due to environmental and human health concerns. Therefore, the purpose of this study is to select an alternative friction material, which is eco-aware lightweight, cost effective, and non-toxic. This will be accomplished using Cambridge Engineering Selector (CES) Edupack software, embedded within an Eco-Audit Tool. For verification, a comparative study using the Pugh method was also investigated. The results show that Kenaf, which is a commodity plant in Malaysia, is the most suitable alternative friction material that passes all of the design stages and consumes less energy, compared to asbestos and other potential materials.
\end{abstract}

Key words: Eco-lightweight / friction materials / CES Edupack / Pugh method

\section{Introduction}

In order to reduce weight, there are two important methods. One of these methods is to redesign the selected parts to optimize their structure. The other method is to replace traditional materials with lightweight materials, such as aluminium alloy, polymer, or composites $[1,2]$. Of these two methods, material replacement is generally more effective in achieving a lightweight than structural modification.

An automotive brake functions by converting the vehicle's kinetic energy into heat energy. The two currently used types of automotive brake friction material are semimetallic and non-asbestos organic (NAO) [3,4]. Automotive brake friction material (i.e., for brake shoes and brake pads) is combination of several materials with unique complex compositions, that are known as binder, reinforcing fiber, filler, and friction modifier [5]. Desirable performance requirements for automotive brake friction materials include stability and a high friction coefficient $(\mu)$ (according to SAE J899a), reduced vibration (judder) and noise, resistance to heat, wear, water, and oil, and absence of damage for the brake disc. A capability of being manufactured with consistency and a reasonable cost $[2,4,6,7]$ are also needed.

${ }^{a}$ Corresponding author: mohdfadzli@utem.edu.my
Although asbestos is used as a friction material, it has been proven to be a human carcinogenic. Therefore, asbestos has been banned by the Environmental Protection Agency (EPA) since 1992 [8]. Since then, the development of potential NAO materials has increased to identify a safer alternative [3,9-15]. A major challenge for this paper is to design and select potential alternative materials that are capable of high performance, lightweight, at an acceptable price, with a low impact to the environment.

The CES Edupack ${ }^{\text {TM }}$ (developed by Ashby et al. at Cambridge University, UK [16]), is a software that provides a database of $>3000$ materials and process information that help in selecting materials and processes to meet the desired complex design requirements. The optimal potential materials can be ranked using the desirable criteria or properties that meet the design's requirement. This software is also provided with Eco-audit, which is able to calculate the embodied energy used and the $\mathrm{CO}_{2}$ produced during five key life phases of a product (i.e., material, manufacture, transport, use, and end of life) [17]. The results produced can be used for targeted environmental impact minimizing parameters.

Thus, the aim of this paper is to select an alternative friction material, which is eco-aware lightweight, cost effective, and non-toxic using a systematic approach. This paper is structured following the basics of the CES Edupack selection material approach, with a short overview 
of the material's selection; design requirement; results of the preliminary material's selection; comparison of the ranked materials series, obtained via eco audit tools; and selection of the best alternative material. For verification, a comparative study using the Pugh method was also investigated.

\section{Material selection steps}

Automotive brake friction materials are considered to be a key safety element of vehicles through their various roles for brake performance, such as stopping distance, pedal feel, disc wear, and brake induced vibrations [28]. Automotive friction materials are required to be strong and able to withstand the braking torque produced during high temperatures and wet or dry environmental conditions [18]. High resistance to wear is a desirable requirement for all automotive friction material, because during the braking process, the friction material is pressed against a rotating brake disc or drum and subjected to wear [19]. If the friction material has a high wear rate, it must be changed more frequently, thus increasing the cost to maintain the performance of the vehicle. Due to kinetics and pressure, heat is produced during braking. Normal operating temperatures recorded usually range from $200-250^{\circ} \mathrm{C}$, and $370^{\circ} \mathrm{C}$ was registered for the front wheel disc pads [20] of passenger cars. For a normal passenger car, typical pressure applied during braking ranged from 0 to $4 \mathrm{MPa}[21,22]$. For safety, a modern brake system is designed for an exerted pressure on the pads of approximately 0-10 MPa.

Developing a successful friction material requires the best balance of factors that yield acceptable performance, cost, and environmental friendliness. Friction materials were generally developed through trial and error, coupled with previous experience of the manufacturer. However, mathematical methods were suggested for evaluation and optimization, such as grey relational analysis [23] and single-criterion extension evaluation method [24]. The correct combination and composition of materials and particle sizes can enhance the tribological performance of the braking interface $[25,26]$.

Safer alternative materials are investigated using CES Edupack software that considers the objectives of this study. The selection method summary is shown in Figure 1. Ashby and Cebon [16] described a solution to materials selection approach using the following five CES steps:

1. Problem definition - product characteristics

a. Function - purpose of the product.

b. Objective of the selection - eco-aware lightweight friction materials.

c. Constraints - stage limit properties for material requirements (criteria) must be met.

2. Objective function - by example, to minimize weight and cost of current components, with the capability to be normally functional, with less environmental impact.

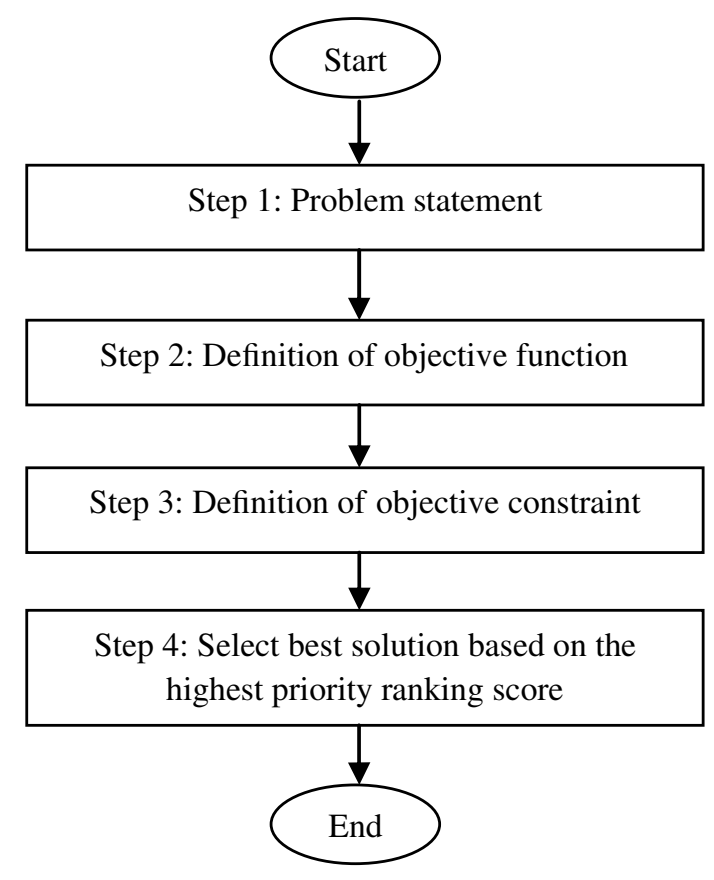

Fig. 1. CES Methodology for material selection.

3. Constraints - stage limit for material selection must be met. This is normally achieved by "performance indices" and "attributes limit". Performance indices for this study were derived from an equation that affects performance material properties, while for attribute limits, maximum and minimum values or properties were filled for the overall assessment of the new design's characteristics, such as durability for water and toxicity.

4. Implementation - of the stage constraints requirement for material selection using CES Edupack material's selection charts. In this study, several material charts were plotted using material properties (or combinations) against each other on logarithmic axes. Performance indices and attributes were used in these charts to identify potential material candidates. Potential materials that met all of the design constraints (stage limits) were evaluated again by Eco-audit to calculate embodied energy and $\mathrm{CO}_{2}$ footprint produced.

5. Interpretation of the results - summarize materials that meet the requirements. Potential materials are ranked following the objectives, in order to select the best material.

\section{Material selection for eco-aware lightweight}

In order to illustrate the material selection approach, straightforward examples were considered. The overall selection process of new eco-aware friction materials is described as follows:

Step 1 - Problem definition.

Asbestos, proven as a human carcinogenic, production for 
Table 1. Function and criteria desired for the eco-aware lightweight friction material.

\begin{tabular}{|c|c|c|}
\hline Function & Criteria & Definition \\
\hline Performance & $\begin{array}{l}\text { i. Strength } \\
\text { ii. Stiffness } \\
\text { iii. Maximum working } \\
\text { temperature } \\
\text { iv. Durability to water }\end{array}$ & $\begin{array}{l}\text { Manage to tolerate or against deflect impact during } \\
\text { braking, are important requirements for automotive brake } \\
\text { friction material to enhance braking performance. Young's } \\
\text { Modulus, Yield Strength, high specific heat, capability to } \\
\text { work, even at high temperatures, wet or dry conditions, are } \\
\text { all key performance parameters. }\end{array}$ \\
\hline Lightweight & i. Density & $\begin{array}{l}\text { To minimize the weight of components and maintain the } \\
\text { required structural strength, and be safe for functional } \\
\text { operation. Capability to reduce weight for fuel efficiency. }\end{array}$ \\
\hline $\begin{array}{l}\text { Product cost } \\
\text { Environmentally friendly }\end{array}$ & $\begin{array}{l}\text { i. Raw material cost } \\
\text { i. Non-toxic } \\
\text { ii. Less energy and } \mathrm{CO}_{2}\end{array}$ & $\begin{array}{l}\text { Minimize product cost and be easily available } \\
\text { For the environment and be potentially safe. }\end{array}$ \\
\hline
\end{tabular}

raw materials was banned. Asbestos is a compulsory material added to automotive friction materials. In order for a safer alternative, developing a NAO is the best solution for replacing asbestos in automotive friction materials.

Step 2 - Definition of objective function.

The objective of this project is to define eco-aware lightweight potential materials, with a capable functional performance, easily available, and at a reasonable cost, using asbestos as a datum. The alternative materials selected must be on a par or have better properties than asbestos, in order to be proven as valid alternatives.

Objective function can be described as the requirements that selected materials must meet, added to the new requirements of an eco-aware lightweight friction material for this study. For example, function stages for new ecoaware lightweight friction materials selected for this study are performance; which is identified through a review of material specifications including, weight, and standard operation performance based on SAE edge code on tribological performance, disposal, environment, and cost. Objective function and specifications for the designed ecoaware lightweight friction material are shown in Figure 2 and elaborated upon further in Table 1.

Step 3 - Definition of objective constraint.

Objective constraint is a sub-function that is considered to meet the objective (or requirements) for the product. For example, to select a material that is strong, stiff, and lightweight, several literatures suggested graphical engineering selections, such as Young's modulus $(E)$ against density $(\rho)$, yield strength $(\sigma)$ against density $(\rho)$ plotted, and performance indices slope $(M)$ are included, aligned with datum by considering equations (1) and (2);

$$
\begin{aligned}
\log E & =3 \log \rho+\log C \\
\log \sigma & =2 \log \rho+\log C
\end{aligned}
$$

where, $E$ is the Young's modulus, $\rho$ is density, and $\sigma$ is yield strength. Materials that lie on the line of constant $E / \rho$ perform equally as light and stiff; those above the line perform better, and those below, less

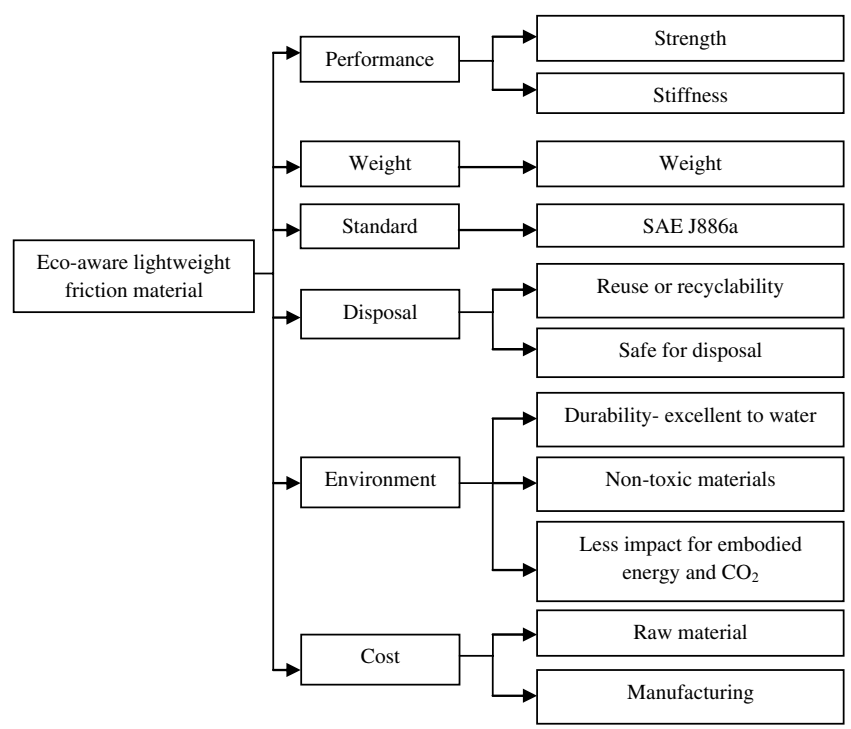

Fig. 2. New automotive eco-aware lightweight friction material's design specifications.

well $[16,27]$. Figures 3 and 4 show graphical charts plotted for lightweight selection materials. In order to identify the functional capability of materials even at high temperatures, materials with higher maximum service, were considered. Therefore, for dry or wet conditions, excellent and acceptable durability properties against water were selected. When considering the environment, materials with toxicity properties were filtered. Considering cost, materials with lower prices were highlighted for further consideration.

Step 4 - Selection material on CES Edupack.

Selection materials constraints and requirements were applied to CES Edupack material software. During material selection, design constraints of acceptable and excellent water durability, toxicity properties, followed by raw material cost strong were selected. Then, several graphical charts were plotted with performance indices 


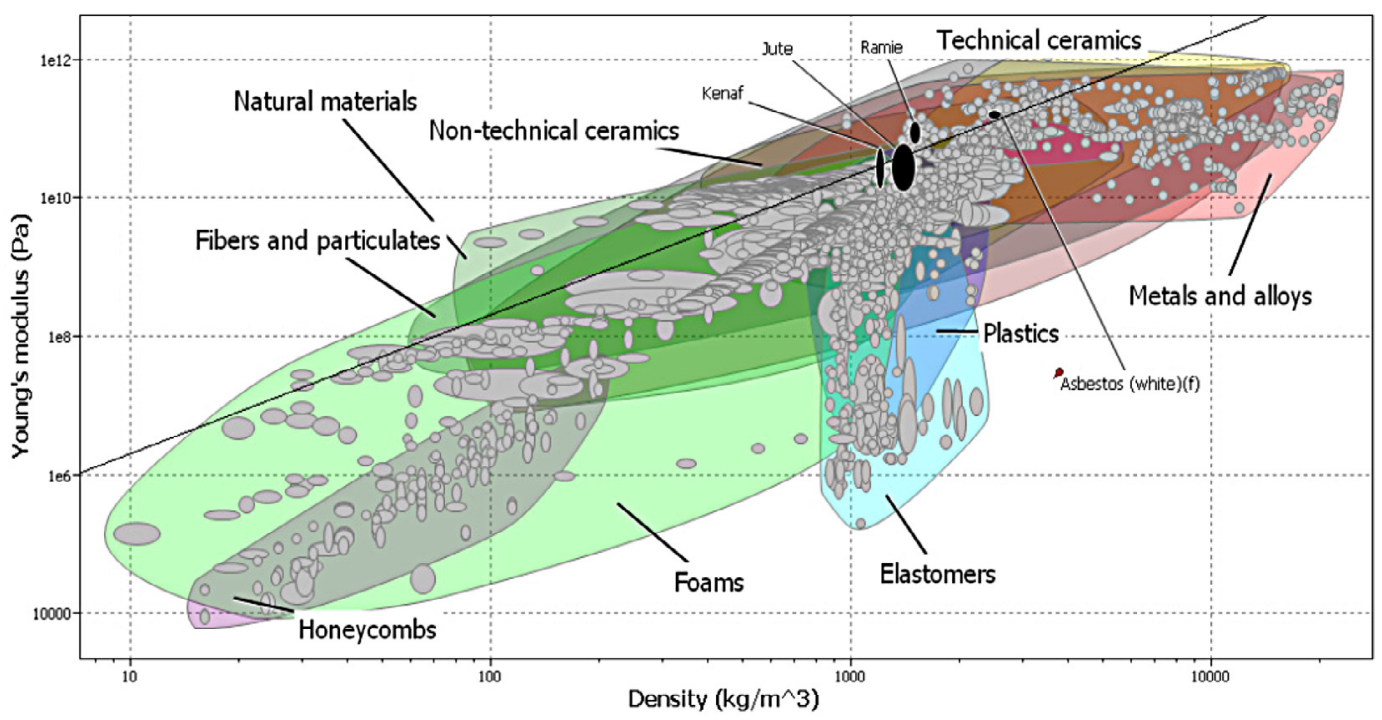

Fig. 3. Plotted graphical material for Young's modulus (Pa) against density $\left(\mathrm{kg} / \mathrm{m}^{3}\right)$.

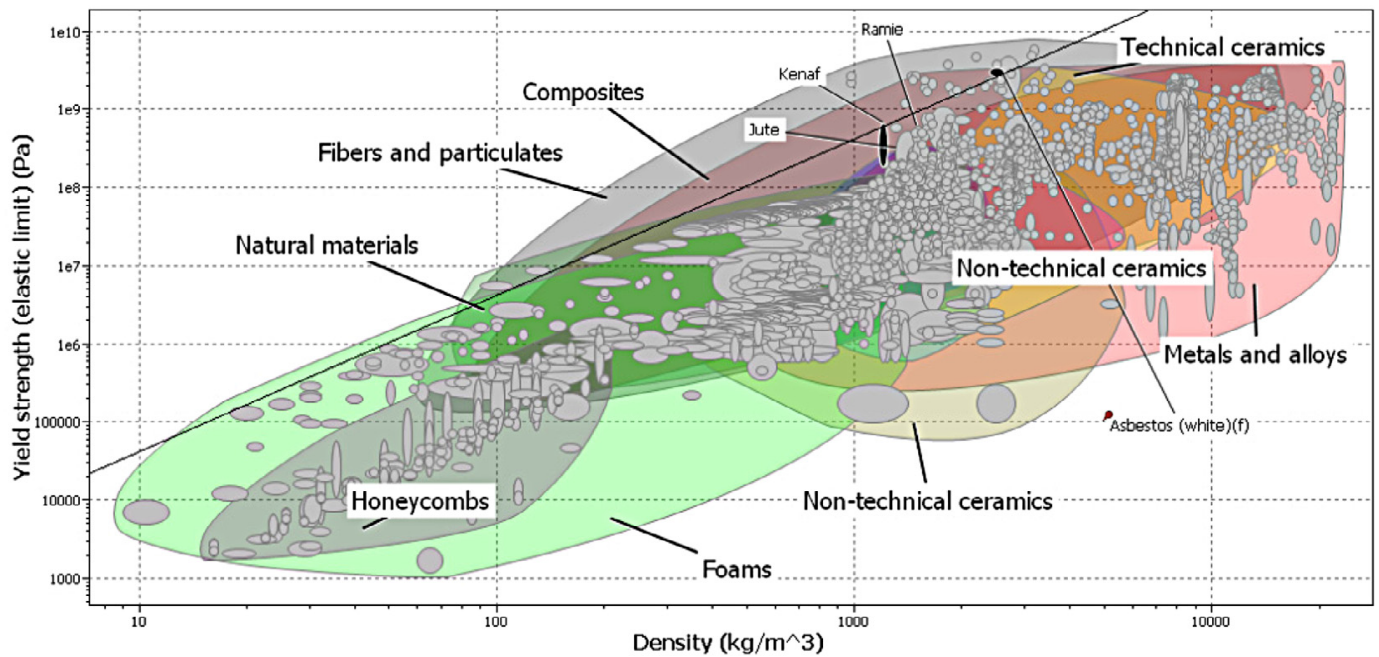

Fig. 4. Shown plotted graphical material for yield strength $(\mathrm{Pa})$ against density $\left(\mathrm{kg} / \mathrm{m}^{3}\right)$.

applied, in order to meet the complex multi-criteria design for the new eco-aware friction material (as shown in Figs. 3 and 4). Materials that meet these specifications are shown by colour, while failed materials are either hidden or transparent. Materials that meet the requirements for strength, stiffness, and being lightweight are lain and upper on the slope and selected for further consideration.

Maximum service temperature materials followed the universal properties database provided by CES Edupack, because the remaining materials were asbestos and Kenaf fibers. Summary results for all design stages are shown in Table 2.

The environmental impact caused by the selected materials was assessed using environmental Life Cycle Assessment (LCA). The assessments were carried out using the Eco audit tools embedded within the CES Edupack software. Two types of input data were used. The first came from a user-entered bill of materials, process choice, transport requirements, and duty cycle. The results were used as a reference source for environmental impacts and other information about the given material's process. Figures 5a and 5b show the comparisons for potential material's embodied energy and $\mathrm{CO}_{2}$ footprint, which could be used to identify materials producing less impact to the environment. Materials that met these requirements were ranked for being lightweight, eco-aware constraint for the selection of new eco-aware lightweight materials to replace asbestos in automotive brake friction materials.

Based on Figures 5a and 5b, total reduction energy and $\mathrm{CO}_{2}$ for Kenaf fibers to the environment were $39 \%$ and $44 \%$, respectively. This proves that Kenaf fiber is a potential material, with less impact to the environment. There are four material comparison phases, namely (extraction from raw material), manufacturer (joint and process), transport (nearest supplier), use, 
Table 2. Summary results for all design stages using CES Edupack.

\begin{tabular}{|c|c|c|c|}
\hline Stage & Attribute & Constraint & Pass \\
\hline \multirow[t]{2}{*}{1} & Toxicity rating & Non-toxic & 2154 \\
\hline & Water (fresh) & Acceptable, Excellent & \\
\hline 2 & Price $(\mathrm{MYR} / \mathrm{kg})$ & 0.0301 to 6.57 & 1007 \\
\hline \multirow[t]{3}{*}{3} & Young's modulus $(\mathrm{Pa})$ & & \\
\hline & $\operatorname{Density}\left(\mathrm{kg} / \mathrm{m}^{3}\right)$ & $\geqslant 3$ & 733 \\
\hline & Performance index & & \\
\hline \multirow[t]{3}{*}{4} & Yield strength (elastic limit) $(\mathrm{Pa})$ & & \\
\hline & Density $\left(\mathrm{kg} / \mathrm{m}^{3}\right)$ & $\geqslant 2$ & 30 \\
\hline & Performance index & & \\
\hline 5 & Records passing: all stages & & 2 \\
\hline
\end{tabular}

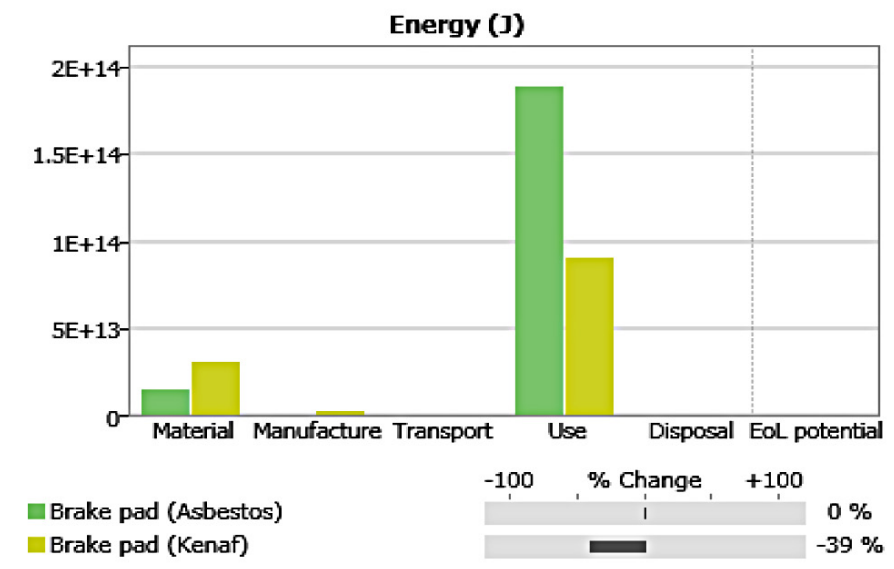

(a)

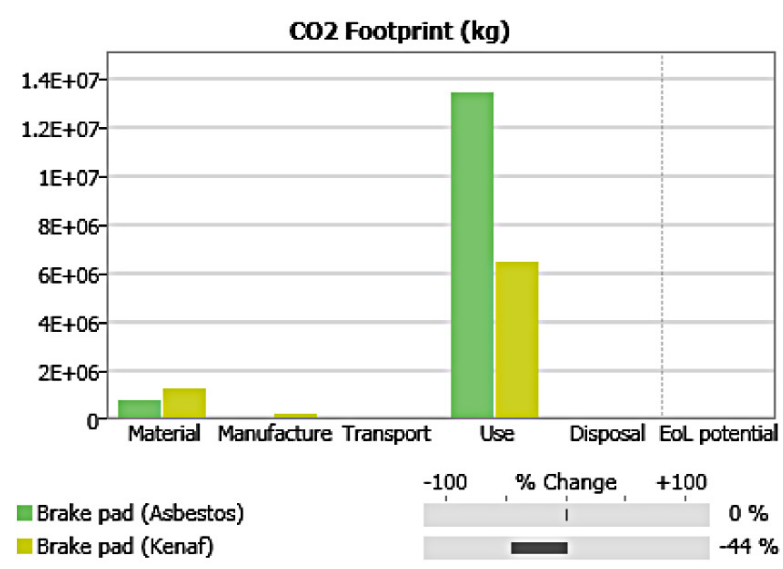

(b)

Fig. 5. Eco-audit results between materials for (a) energy and (b) $\mathrm{CO}_{2}$ footprint.

and $\%$ changes that contain overall fractions for both materials. According to O' Hare et al. [17], the most dominant changes of energy and $\mathrm{CO}_{2}$ can be selected; if the gap already contains a big difference. Therefore, Kenaf was chosen as the material that had less impact to the environment.

\section{Comparison using the Pugh method}

Based on the CES Edupack's report, natural organic Kenaf fibers were selected for the most suitable replacement of asbestos. Therefore, comparison and justification using the Pugh method between asbestos, Kenaf fibers, and several organic fibers, was used to select the best materials between natural organics. The results are summarized in Table 3.

Results and properties selected for jute and ramie fibers were taken from the CES universal properties database in a raw state for proper comparison. The selection of materials followed the objective of eco-aware lightweight friction material in this study to neglect biases or random states. The signs used to represent property values for comparison were equal $(=)$ mean on the safe range, minus $(-)$ for less improvement, and $(+)$ for better improvement.

Designed values and typical pressures recorded for passenger cars ranged from $0-10 \mathrm{MPa}$. This shows that all organic fibers selected were within the range, and able to tolerate against impacts during braking. However, when considering weight, the most lightweight material of all was Kenaf fiber, followed by jute, ramie, and finally, asbestos. Therefore, a plus $(+)$ sign was used for all natural fibers, when considering materials that were more lightweight and more non-toxic than asbestos.

Maximum temperatures recorded were $250{ }^{\circ} \mathrm{C}$ for lining shoes and $370^{\circ} \mathrm{C}$ for disc brakes. Therefore, the limitation for the friction material is the capability to function normally up to these temperatures. Based on these results, all of the selected materials met this requirement and an equal (=) sign was used. Another requirement for the eco-aware friction material is the capability to perform normally in both dry and wet conditions. Therefore, the constraint for this property must be an excellent or acceptable durability against water. Technically, the results for the selected materials (based on the CES Edupack's universal database) were that all natural organics can tolerate against water. Therefore, an equal (=) sign was issued to represent these properties.

Price and cost are considered important to the overall selection of an eco-aware lightweight friction material, in order to reduce costs for the production of this product. Based on the results, Kenaf fibers showed the lowest price, followed by jute fibers, asbestos, and ramie (ramie was considered expensive because of a price higher than 
Table 3. Summary of results for properties between asbestos and several natural organics.

\begin{tabular}{lcccc}
\hline General properties & Asbestos & Kenaf fibers & Jute fibers & Ramie fibers \\
\hline Strength (MPa) & 3140 & 361 & 277 & 469 \\
Stiffness (GPa) & 165 & 27.2 & 27.9 & 88.7 \\
Density $\left(\mathrm{kg} / \mathrm{m}^{3}\right)$ & 2500 & 1190 & 1400 & 1500 \\
Price $(\mathrm{MYR} / \mathrm{kg})$ & 5.78 & 1.15 & 2.26 & 6.04 \\
Toxicity rate & Toxic & Non-toxic & Non-toxic & Non-toxic \\
Maximum service temperature $\left({ }^{\circ} \mathrm{C}\right)$ & 914 & 410 & 410 & 410 \\
Durability Water (fresh) & Excellent & Acceptable & Acceptable & Excellent \\
Embodied energy (\% change) & Datum & $-39 \%$ & -31 & -40 \\
$\mathrm{CO}_{2}$ footprint (\% change) & Datum & $-44 \%$ & -37 & -40 \\
\hline
\end{tabular}

Table 4. Pugh method objective and function results.

\begin{tabular}{lcccc}
\hline Function & Asbestos & Kenaf fibers & Jute fibers & Ramie fibers \\
\hline Strength $(\mathrm{MPa})$ & & - & - & - \\
Stiffness $(\mathrm{GPa})$ & - & - & - \\
Density $\left(\mathrm{kg} / \mathrm{m}^{3}\right)$ & & + & + & + \\
Price $(\mathrm{MYR} / \mathrm{kg})$ & $\Xi$ & + & + & - \\
Toxicity rate & $\Xi$ & + & + & + \\
Maximum service temperature $\left({ }^{\circ} \mathrm{C}\right)$ & - & $=$ & $=$ & $=$ \\
Durability Water (fresh) & & $=$ & $=$ & $=$ \\
Embodied energy $(\%$ change) & & + & + & + \\
$\mathrm{CO}_{2}$ footprint $(\%$ change) & + & + & + \\
\hline Total & & +5 & +5 & +4 \\
\hline
\end{tabular}

Indicator: = equally; + better; - lower.

the datum). Results from the Pugh method evaluation are shown in Table 4, while other categories followed the function objectives.

From the Pugh method's results, Kenaf fiber and jute fibers were selected as suitable asbestos replacement materials for eco-aware lightweight friction material. However, according to eco-aware, lightweight, and cost, Kenaf fibers were selected as better, due to their lower impact energy and $\mathrm{CO}_{2}$, being the lightest and the cheapest of all materials. Therefore, Kenaf fibers were selected as being more suitable than jute fibers using the Pugh method.

\section{Conclusion}

Pre-selection for an alternative material to asbestos, to be included as an automotive friction material, was performed using CES Edupack software, based on a formulated design and its requirements. Through all of the criteria and the constraints, Kenaf fibers were identified as being the best material of all, which pass all the design requirements. This was proved using Pugh's method, where the results show a promising potential for Kenaf fibers by capability on eco-aware with reduction impact to the environment, lightest, and the cheapest.

Acknowledgements. The authors gratefully acknowledge contributions from the members of the Green Tribology and Engine Performance (G-TriboE) research group. This research is supported by the grants from the Ministry of Education
Malaysia (Grant Nos.: RAGS/2013/FKM/TK01/03/B00042 and ERGS/2013/FKM/TK01/UTEM /02/04/E00016).

\section{References}

[1] Y. Zhang, X. Lai, P. Zhu, W. Wang, Mater. Design 27 (2006) 64-68

[2] M.F.B. Abdollah, R. Hassan, J. Mech. Eng. Technol. 5 (2013) 11-18

[3] D. Chan, G.W. Stachpwiak, Proc. Instit. Mech. Eng. D: J. Automobile Eng. 218 (2004) 953-966

[4] P.J. Blau, Compositions, Functions, and Testing of Friction Materials and Their Additives. OAK Ridge National Laboratory Report ORNL/TM 2001/64, Oak Ridge, Tennesse, 2001, pp. 1-29

[5] M. Eriksson, F. Bergman, S. Jacobson, Wear 232 (1999) 163-167

[6] F. Bergman, M. Eriksson, S. Jacobson, Wear 299 (1999) $62-628$

[7] S. Kim, H. Jang, Tribol. Int. 33 (2000) 477-484

[8] C. Ramazzini, Call for an International Ban on Asbestos, Environment Resolution 83 (2000) 79-81

[9] L. Han, L. Huang, J. Zhang, Y. Lu, Sci. Technol. 66 (2006) 505-513

[10] B.F. Yousif, U. Nirmal, K.J. Wong, Composite 31 (2010) 4514-4521

[11] S.A.R. Hashmi, U.K. Dwivedi, G. Navin, Wear 262 (2007) 1426-1432

[12] B.A. Acha, N.E. Marcovich, M.M. Reboredo, J. Polymer Sci. 262 (2005) 736-741

[13] Q. Liu, M. Hughes, Composites A: Appl. Sci. Manufact. 39 (2011) 1644-1652 
[14] N.S.M. El-Tayeb, Wear 39 (2008) 223-235

[15] M. Yunhai, S. Shenglong, T. Jin, Y. Wei, Y. Yazhou, Z. Jiang, J. Thermoplastic Composite Mater. 26 (2010) 845-859

[16] M.F. Ashby, D. Cebon, Teaching Engineering Materials: The CES Edupack. Engineering Department, Cambridge University, 2007, pp. 1-13

[17] J. O'Hare, E. Cope, S. Warde, Five steps to Eco Design, Improving the Environmental Performance of Products through Design. Granta Design Limited, 2011, pp. 1-12

[18] S. Katsuhiro, G. Akira, Y. Satoshi, A. Yuichi, N. Koji, Development of Brake Friction Material, Honda Research and Development Co. Ltd., 1993, pp. 149-161

[19] R.J. Talib, S.S. Mohmad, and K. Ramlan, Selection of Best Formulation for Semi-Metallic Brake Friction Materials Development, Powder Metallurgy, Dr Katsuyoshi Kondoh (Ed.), ISBN:978-953-51-0071-3, InTech. Available from: http://www.intechopen. com/books/powder-metallurgy/Selection-of-BestFormulation-for-Semi-Metallic-Brake-FrictionMaterials-Development, 2012.
[20] M.G. Jacko, S.K. Rhee, B. Linings, C. Facing, In: M. Grayson, (ed.), Encyclopedia of Composite Materials and Component, John Wiley and Sons, USA, 1995, pp. 144154

[21] N.M. Kinkaid, O.M. O'Reilly, P. Papadopoulos, J. Sound Vib. 267 (2003) 105-166

[22] G. Cueva, A. Sinatora, W.L. Guesser, A.P. Tschiptschin, Wear 255 (2003) 1256-1260

[23] L. Han, L. Huang, J. Zhang, Y. Lu, Compos. Sci. Technol. 66 (2006) 2895-2906

[24] R. Yun, Y. Lu, P. Filip, Tribology Int. 43 (2010) 2010-2019

[25] N.S.M. EL-Tayeb, K.W. Liew, Wear 266 (2009) 275-287

[26] K.S. Bhabani, P. Amar, D. Nandan, R. Prasanta, S.T. Bharat, J. Eng. Technol. 226 (2012) 439-445

[27] M.F. Ashby, D. Cebon, Case studies in material selection, Granta Design Limited, Cambridge, 1996

[28] Y.C. Kima, M.H. Cho, S.J. Kim, H. Jang, Wear 264 (2008) 204-210 